DOI: $10.20472 / E F C .2018 .009 .004$

\author{
ABDUL HAQUE \\ COMSAT Institute of Information Technology, Lahore, Pakistan
}

ADEEL NASIR

University of the Punjab, Jhelum Campus, Pakistan

\title{
THE APPLICATION OF VALUE AT RISK AND EXPECTED SHORTFALL AS CONTROLLING MECHANISM OF SYSTEMATIC RISK OF PAKISTANI STOCK MARKET
}

\begin{abstract}
:
Fama and French (1992) three factor and Fama and French (2014) five-factor Model estimated relevant idiosyncratic factors and CAPM beta as the systematic risk factor for stock returns' variations. Application of Value at Risk (VaR) and Expected Shortfall (ES) modified the risk management criteria. This study applies traditional one factor, three factor and five factor model on Pakistan's manufacturing companies. Compares and modifies the stated models while using VaR and ES as systematic risk factor and check the robustness of the significant extent of worst expected loss provided by VaR and ES by measuring $95 \%$ and $99 \%$ confidence levels and their impact on the stock returns. In comparison with traditional market risk factor, our findings are in favor of VaR and ES factor as it significantly affects the cross-sectional of excess stock returns and fulfills the criteria of risk aversion.
\end{abstract}

\section{Keywords:}

Value at Risk, Expected Shortfall, Fama and French Three Factor Model, Five Factor Model, Systematic Risk, Idiosyncratic Risk

JEL Classification: G10, G11, G14 


\section{Introduction}

The risk is a subjective phenomenon and asymmetric situation, which may arise whenever there is predetermine uncertainty and it is related to lose. Risk of investment in securities can be defined as the chance of getting a different outcome from investment against the expectations of investors (Grundy \& Malkiel, 1996). The global financial crisis ${ }^{1}$ advocates the need for the practical and authentic rfisk mitigation tools in security markets. The formation of correct risk management mechanism is a challenge for institutions and regulators. If there is a source by which we can quantify and measure risk associated with our investment portfolios, then we can construct major risk contributors, diversify, minimize and ultimately rebalance the potential portfolio risk. The portfolio assumption indicates that investors are mostly risk averse, this assumption leads to the basic expectation that risk is positively related to return (Sharpe, 1964 and Lintner, 1965). The positive relationship between market beta and stock returns, Fama \& MacBeth (1973) found the same relationship in crosssection of stock returns, however, reported the weak relationship of beta with NYSE stock returns. Size and book to market ratio (Fama \& MacBeth, 1973) and value factor (Basu, 1983; Fama \& French, 1989, 1993; Lewellen, 1999; Nelson, 1999 played significant role in accessing the stock returns. In addition to size and value factor, there are two more asset pricing anomalies i.e. profitability and investment. These two risk factors are considered from the dividend discount model provided by Markowitz (1952). A strong relationship was observed between average returns of securities and profitability. Three-factor model did not capture the effect of profitability on stock returns and the five-factor model did not consider as fitted asset pricing model. The former findings are interesting because this study separately analyzed the one factor, three factor, and five-factor model.

Value at Risk ( $\mathrm{VaR})$ is defined as the maximum loss over the given time horizon at some given confidence level. Value at Risk measures the maximum loss of certain security or bond at some probability and over some horizon (e.g. 1 or 10 days). Expected Shortfall (ES) or Conditional Value at Risk (CVaR) is the risk assessment model, but unlike $\mathrm{VaR}$, which specifies the worst expected loss, ES provides an average of extreme losses. In other words, $\mathrm{VaR}$ measures the maximum possible loss that investor might face on investment or portfolio of investments (Jorion, 2002, 2006). Scheule, Kellner, and Rösch (2016) specified that VaR and ES are less prone to misspecification and provide significant risk estimation. They analyzed the accuracy of $\mathrm{VaR}$ and ES at 95\% and 99\% level of confidence. Degiannakis \& Potamia (2017) check the intraday reliability of $\mathrm{VaR}$ and ES predictions with the recommendations of basel committee of banking supervision. The multiple periods $\mathrm{VaR}$ and ES predictions are adequate for $95 \%$ level of confidence. $97.5 \%$ level of confidence was introduced in revised Basel III accord and provided accurate results for stock indices. The study advocates the model provided by Chen, Chen, and Wu (2014), who investigated the

\footnotetext{
1 Black Monday of October 19, 1987 when S\&P 500 fell more than $20 \%$ in one day, the hedge fund crises of 1998 , Asian financial crises of 1997-1998, global financial crises of 2007
} 
effect of market beta, $\mathrm{VaR}$, size and value factor on the cross section of the underdeveloped stock market of Taiwan. There is a marginal explanation provided by the $\mathrm{VaR}$ in traditional three-factor model. The popularity of $\mathrm{VaR}$ is due to the negative cauterization of scenario in stock markets.

Pakistan stock exchange (PSX) was established on 11 th January-2016 due to the merger of other three stock exchanges i.e. Karachi, Lahore and Islamabad located in Karachi Pakistan under the company ordinance 1984. KSE 100 index is considered as the barometer of the market and used to analyze the market returns in this study. Figure 1 shows the stable increase in index value. Then exchange smoothly moved on the development track and from 2000 to 2005. However, 2006 to 2010 time frame had many ups and down expressions. Global crises, financial instability and many other factors are said to responsible for the negligence. After that time, the exchange grows positively till now but many obvious ups, and down in exchange.

\section{Figure 1. KSE 100 Index Yearly Data Analysis}

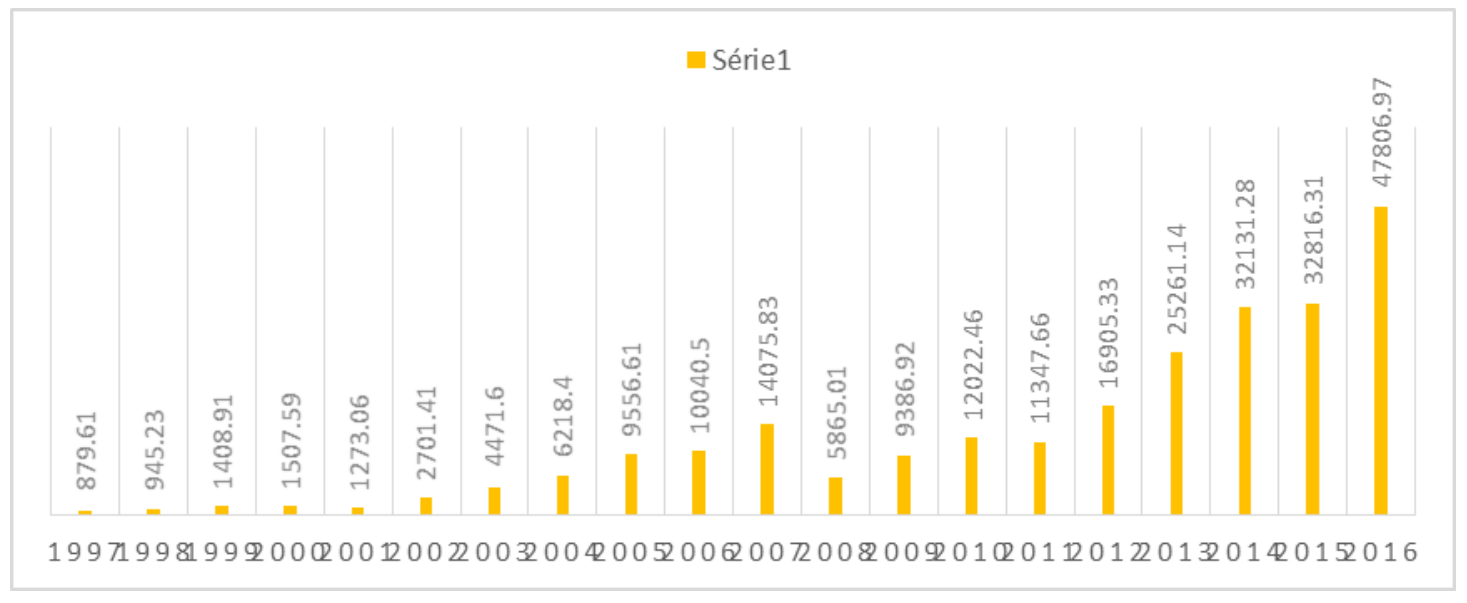

Figure 2. Returns of KSE 100 Index from 1998 to 2016

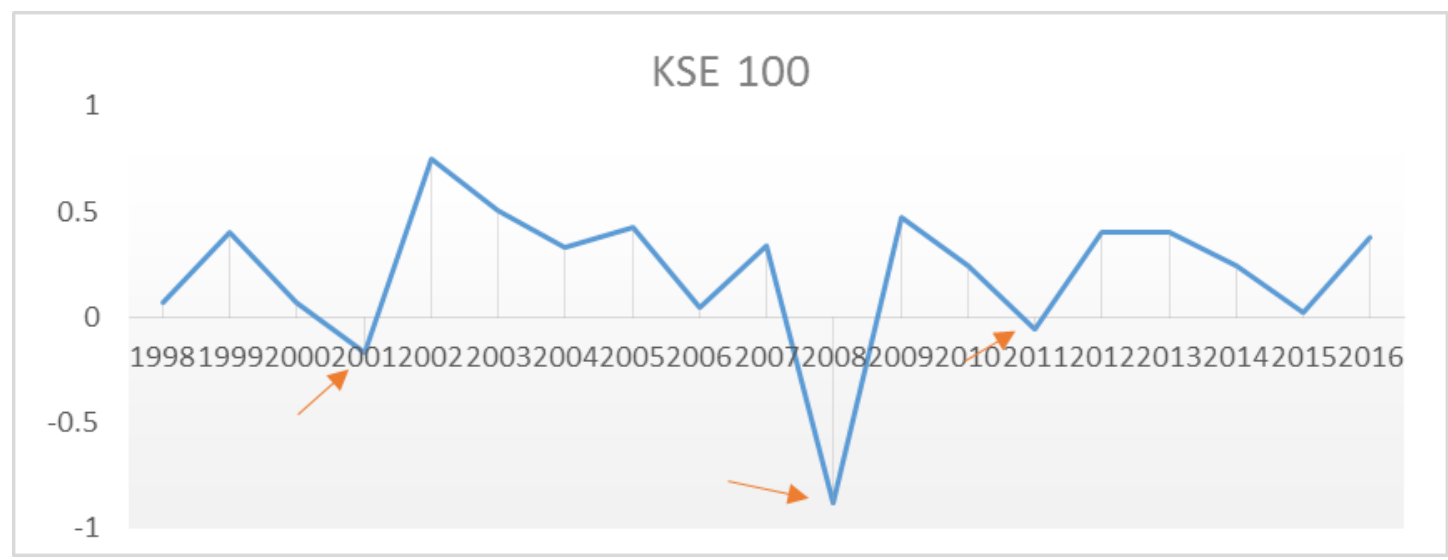

Figure 2 shows volatile positive and negative returns from past couple of years. Negative returns in the figure, which are below zero points, show that market crashed 
those years (2001, 2008 and 2011) and positive returns show that market was at the boom in that years.

This objective of this study to find the optimal portfolio by applying Sharpe (1965), Lintner (1965), Black (1972), Fama and French three factor model (1992) and five factor model (2014). In addition to the significance of stated model, this study implements $\mathrm{VaR}$ and $\mathrm{ES}$ as the controlling mechanism of systematic risk in Pakistani stock market.

\section{Research Methodology}

The sample companies are selected which are listed in PSX ${ }^{2}$ from 1998 to 2015. Data is adjusted according to delisting, mergers and acquisitions and bankruptcy. Annual data of log of market equity (InME), a book to market equity (BM), operating profitability (OP), investment (INV), VaR and ES for each company at $95 \%$ and $99 \%$ level of significance.

Stock excess returns are formulated with security returns minus the risk-free rate of returns (T-bills). Daily returns are observed for 1998 to 2014, collected from PSX and state bank of Pakistan

CAPM model indicated that there is a significant positive relationship between risk and returns (Sharpe, 1964).

$(\mathrm{Ri}-\mathrm{Rf})_{\mathrm{t}}=\alpha_{\mathrm{t}}+\beta_{1}(\mathrm{Rm}-\mathrm{Rf})_{\mathrm{t}}+\varepsilon \mathrm{t}$

Where (Ri-Rf) is the excess returns calculated by returns of security minus the riskfree rate of return. (Rm-Rf) indicates the market return minus risk-free rate of return.

According to Jorion (2006), VaR measures the risk of the security in a systematic fashion. For VaR the researcher will find the parametric VaR for each security by the following formula

$V A R \alpha=Z a \sigma$

The above equation represents the value at risk at some confidence level (VaRa) which is calculated on the basis a critical value (99\% and $95 \%)$ and volatility of stock returns.

ES models will be used to provide more robust market risk measure of VaR. ES or CVaR provides analysis by average extreme events.

$C V A R=\gamma V a R+(1-\gamma) C V A R, 0 \leq \mathrm{\gamma} \leq 1$

${ }^{2}$ Formally known as Karachi Stock Exchange 
Equation (3) measures the ES of securities returns. It identifies average of worst expected loss.

\section{Cross Sectional Variation of Stock Returns}

According to Sharpe (1964), Lintner (1965) and Black (1972) market efficiency depends upon the positive linear relationship of market portfolios expected returns and market betas. The study elaborates the cross-sectional variation in stock returns using CAPM, VaR and ES models.

\section{Market Excess Returns and Idiosyncratic Risk Factors}

The study conducts the traditional cross-sectional analysis using market beta size, value, growth, investment, and profitability.

$\mathrm{R}_{\mathrm{i}}-\mathrm{R}_{\mathrm{f}}=\alpha_{i}+\gamma_{1}$ Market $-\beta_{\mathrm{i}}+\varepsilon_{\mathrm{i}}$

The above equation analyzes the single factor effect advocated by Sharpe (1964), Lintner (1965) and Black (1972). Equation 4 test the effect of market beta on crosssectional of stock excess return

$R_{i}-R_{f}=\alpha_{i}+\gamma_{1}$ Market $-\beta_{i}+\gamma_{2} \ln (M E)_{i}+\gamma_{3} B M_{i}+\varepsilon_{i}$

Model 5 is advocated by Fama and French (1992 and 1993) three factor model. The model analysis the effect of market beta as the systematic effect and also state the diversifiable effect of size (LnME) and value (BM) factor.

$\mathrm{R}_{\mathrm{i}}-\mathrm{R}_{\mathrm{f}}=\alpha_{\mathrm{i}}+\mathrm{\gamma}_{1}$ Market $-\beta_{i}+\mathrm{\gamma}_{2} \ln (M E)_{i}+\mathrm{\gamma}_{3} B M_{i}+\mathrm{\gamma}_{4} O P_{i}+\mathrm{\gamma}_{4} / N V_{i}+\varepsilon_{i}$

Where Market- $\beta$ represents the systematic risk effect. $\operatorname{Ln}(\mathrm{ME})$ is the log of market equity of current year i.e. $t$ representing idiosyncratic risk effect of size factor; BM is the book to the market ratio at time $t$ providing value effect. INV is investment factor calculated by the change in the total asset to $t-1$ from $t-2$. OP is profitability factor calculated by earnings before interest and taxes in $t-1$ divided by the book to the market ratio in $t-1$.

\section{Value at Risk models and idiosyncratic risk factors}

The Objective of this study is to analyze the optimal systematic controlling mechanism with application of VaR and ES to one factor, three factor and five factor model.

$$
\mathrm{R}_{\mathrm{i}}-\mathrm{R}_{\mathrm{f}}=\alpha_{i}+\gamma_{1} V a R_{i}+\varepsilon_{i}
$$

Where $\mathrm{VaR}$ is the annual value at risk stocks representing the systematic downside risk. two confidence levels are used i.e. $95 \%$ and $99 \%$. 
$\mathrm{R}_{\mathrm{i}}-\mathrm{R}_{\mathrm{f}}=\alpha_{i}+\gamma_{1} E S_{i}+\varepsilon_{i}$

Here the model uses the ES as the controlling mechanism of systematic risk. The study uses both $95 \%$ and $99 \%$ level of confidence for robust estimation of single factor model.

$R_{i}-R_{f}=\alpha_{i}+y_{1} V a R_{i}+y_{2} \ln (M E)_{i}+\gamma_{3} B M_{i}+\varepsilon_{i}$

Equation 9 contributes with the three factor model using VaR, at $95 \%$ and $99 \%$ level of confidence, as the systematic risk factor and log of market equity (LnME) and book to market ratio $(B M)$ as idiosyncratic risk factors estimating the cross sectional of stock excess returns.

$R_{i}-R_{f}=\alpha_{i}+\gamma_{1} E S_{i}+\gamma_{2} \ln (M E)_{i}+\gamma_{3} B M_{i}+\varepsilon_{i}$

Where ES represents the average of worst expected loss. It is used as the systematic risk factor with idiosyncratic risk factors i.e. Size factor (LnME) and value factor (BM).

$$
\begin{aligned}
& R_{i}-R_{f}=\alpha_{i}+\gamma_{1} V a R_{i}+\gamma_{2} I n(M E)_{i}+\gamma_{3} B M_{i}+\gamma_{4} I N V_{i}+\gamma_{4} O P_{i}+\varepsilon_{i} \\
& R_{i}-R_{f}=\alpha_{i}+\gamma_{1} E S_{i}+\gamma_{2} \ln (M E)_{i}+\gamma_{3} B M_{i}+\gamma_{4} I N V_{i}+\gamma_{4} O P_{i}+\varepsilon_{i}
\end{aligned}
$$

Equation 11 and 12 uses VaR and ES as the contributory systematic risk factor in addition to the Fama and French (2014) five factor model.

\section{Cross-Sectional Regression Analysis}

This section provides a controlling mechanism for systematic and idiosyncratic risk effecting cross-sectional of stock returns. The size of stock, value, growth, investment, and profitability has provided contemporary significance in controlling idiosyncratic risk return dynamics in developed nations (Xue, \& Zhang, 2014). 


\section{Table 1. Cross-sectional regression of Systematic Risk and Return Analysis}

The model represents the cross-sectional regression model with excess stock returns as the dependent variable. Systematic risk and return relationship are observed with Sharpe, Lintner and Black CAPM model, VaR and ES model using 95\% and $99 \%$ confidence level. P-value is provided in parenthesis and italic font specifying the significance of the effect of the variable.

\begin{tabular}{|c|c|c|c|c|c|}
\hline & Ri-Rf & & & & \\
\hline & 1 & 2 & 3 & 4 & 5 \\
\hline BETA & $\begin{array}{l}-0.00199 \\
(0.0000)\end{array}$ & & & & \\
\hline VaR 95 & & $\begin{array}{l}0.003085 \\
(0.0000)\end{array}$ & & & \\
\hline VaR 99 & & & $\begin{array}{l}0.003372 \\
(0.0000)\end{array}$ & & \\
\hline ES 95 & & & & $\begin{array}{l}0.086408 \\
(0.0000)\end{array}$ & \\
\hline ES 99 & & & & & $\begin{array}{l}0.341012 \\
(0.0000)\end{array}$ \\
\hline C & $\begin{array}{l}0.001159 \\
(0.0000)\end{array}$ & $\begin{array}{l}0.000489 \\
(0.0000)\end{array}$ & $\begin{array}{l}0.000816 \\
(0.0000)\end{array}$ & $\begin{array}{l}0.000774 \\
(0.0000)\end{array}$ & $\begin{array}{l}0.000895 \\
(0.0000)\end{array}$ \\
\hline
\end{tabular}

The above table shows the relationship of systematic risk factors with excess stock returns. A theoretical perspective which was provided by Markowitz (1952) mentioned the positive risk and returned relationship. In Pakistan, the stock market beta has a significant result, but there is a negative relationship between market beta and excess returns which advocate the concept of short-selling and speculation in the market. There is positive significant effect of $\mathrm{VaR}$ and ES on cross sectional of excess stock returns, advocating the desired risk averse behavior of investors. ES beta at $99 \%$ level of significance makes the excess stock returns most sensitive of all models reported, which might lead towards the optimal risk return tradeoff in PSX.

\section{Table 2. Cross-Sectional Regression of Three Factor Model}

The table represents five equations with a three-factor model representing controlling mechanism of idiosyncratic risk i.e. the log of market equity (a proxy for size), and a log of the book to market equity ( a proxy of value factor). All models combined to represent the comparison between different controlling mechanisms of systematic risk i.e. tradition beta, VaR at $95 \%$ and $99 \%$ and ES at $95 \%$ and $99 \%$. The dependent variable is the excess return of companies listed in PSX. Excess returns are calculated by subtracting security return from risk-free rate of return. T-Bills rates are used as the risk-free rate of returns. Predicted values are each independent variable and P-values are provided in parenthesis and italic font specifying the significance of the variable.

\begin{tabular}{|c|c|c|c|c|c|}
\hline & \multicolumn{5}{|l|}{$\mathrm{Ri}-\mathrm{Rf}$} \\
\hline & 5 & 6 & 7 & 8 & 9 \\
\hline BETA & $\begin{array}{l}-0.00352 \\
(0.0000)\end{array}$ & & & & \\
\hline VaR 95 & & & & & \\
\hline
\end{tabular}




\begin{tabular}{|c|c|c|c|c|c|}
\hline & & $(0.0000)$ & & & \\
\hline VaR 99 & & & $\begin{array}{l}0.005826 \\
(0.0000)\end{array}$ & & \\
\hline S 95 & & & & $\begin{array}{l}0.10716 \\
(0.0000)\end{array}$ & \\
\hline S 99 & & & & & $\begin{array}{l}0.485541 \\
(0.0000)\end{array}$ \\
\hline LNME & $\begin{array}{l}0.004412 \\
(0.0000)\end{array}$ & $\begin{array}{l}\text { 6.39E-05 } \\
(0.8514)\end{array}$ & $\begin{array}{l}-0.00152 \\
(0.0211)\end{array}$ & $\begin{array}{l}-0.00072 \\
(0.2713)\end{array}$ & $\begin{array}{l}-0.00141 \\
(0.0335)\end{array}$ \\
\hline LNBM & $\begin{array}{l}0.000714 \\
(0.0000)\end{array}$ & $\begin{array}{l}0.000375 \\
(0.0000)\end{array}$ & $\begin{array}{l}0.000398 \\
(0.0000)\end{array}$ & $\begin{array}{l}0.000416 \\
(0.0000)\end{array}$ & $\begin{array}{l}0.000387 \\
(0.0000)\end{array}$ \\
\hline C & $\begin{array}{l}-0.00966 \\
(0.0000)\end{array}$ & $\begin{array}{l}0.000211 \\
(0.8132)\end{array}$ & $\begin{array}{l}0.004772 \\
(0.0058)\end{array}$ & $\begin{array}{l}0.002515 \\
(0.1434)\end{array}$ & $\begin{array}{l}0.004466 \\
(0.0103)\end{array}$ \\
\hline
\end{tabular}

In three factor model CAPM beta does not loose its negative effect on stock excess returns. Both size and value anomalies are relevant with CAPM beta. Size anomaly loses its effect when VaR and ES are used as the controlling machenism of systematic risk. Cross sectional of excess stock returns are most effected by ES beta at $99 \%$ level of confidence. Value factor has significant effect on stock returns. Alpha values are insignificant for VaR 95\% and ES models representing optimal outcomes.

\section{Table 3. Cross-Sectional Regression of Five Factor Model}

The table represents five equations with five-factor models estimation with controlling mechanism of idiosyncratic risk i.e. the log of market equity (a proxy of size) and a log of the book to market equity (a proxy of value factor), investment (INV) factor and profitability (OP) factor. All models combined, represent the comparison between different controlling mechanisms of systematic risk i.e. tradition beta, value at risk at $95 \%$ and $99 \%$ and expected shortfall at $95 \%$ and $99 \%$. The dependent variable is the excess return of companies listed in PSX. Excess returns are calculated by subtracting security return from risk-free rate of return. T-Bills rates are used as the risk-free rate of returns. Predicted values are each independent variable and P-values are provided in parenthesis and italic font specifying the significance of the variable.

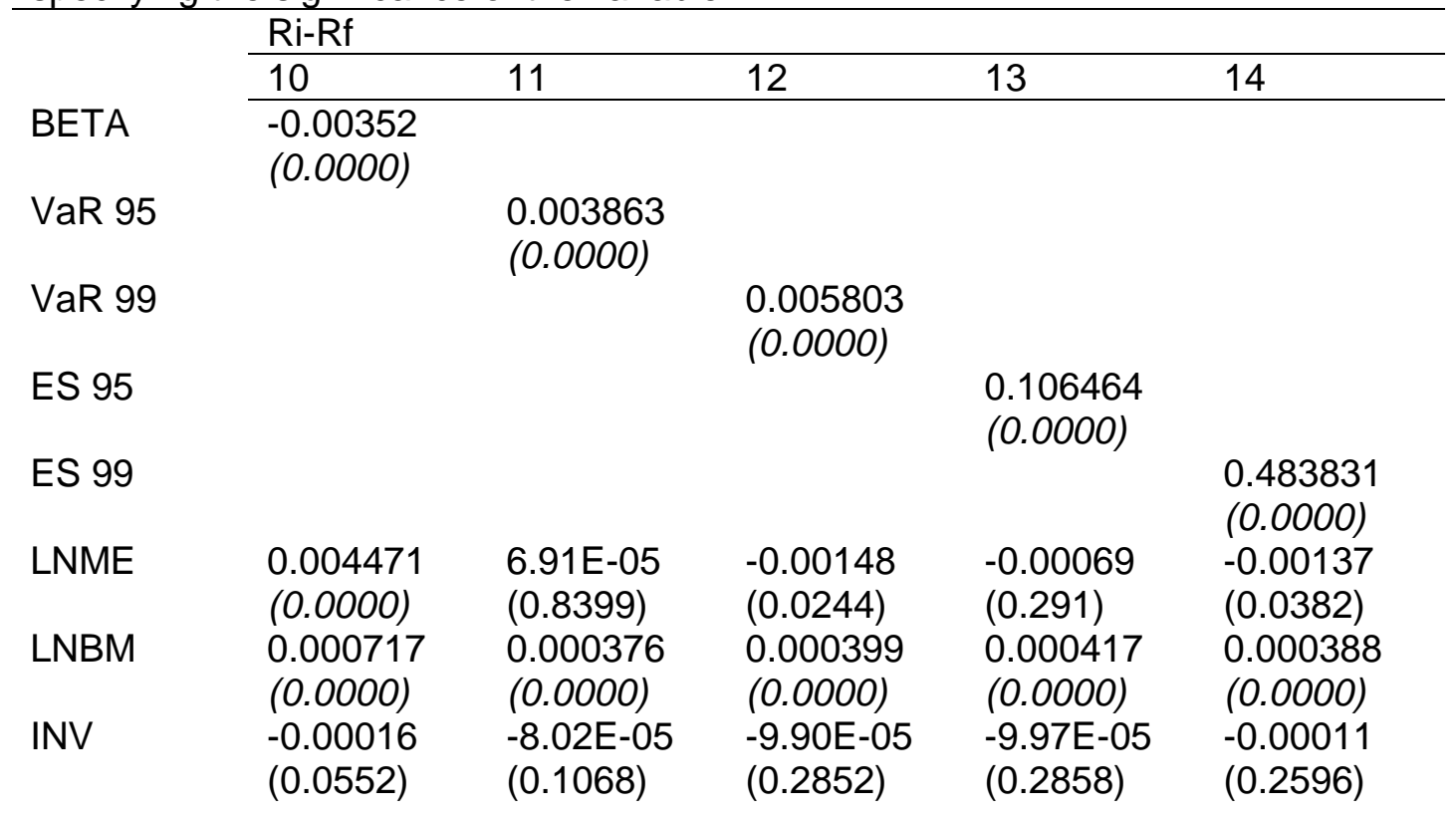




\begin{tabular}{llllll} 
OP & $2.76 \mathrm{E}-05$ & $6.49 \mathrm{E}-05$ & $3.55 \mathrm{E}-05$ & $4.80 \mathrm{E}-05$ & $4.05 \mathrm{E}-05$ \\
& $(0.5849)$ & $(0.0353)$ & $(0.5366)$ & $(0.4067)$ & $(0.4818)$ \\
$\mathrm{C}$ & -0.00979 & 0.0002 & 0.004695 & 0.002452 & 0.004392 \\
& $(0.0000)$ & $(0.8229)$ & $(0.0068)$ & $(0.1545)$ & $(0.0118)$ \\
\hline
\end{tabular}

In the contemporary financial world, five-factor model has its significance. Nguyen Nhu et al. (2015) studied the significance of Fama \& French (2014) five-factor model in Vietnam. Kubota \& Takehara (2017) analyses the significance of five factor model in Japanese market which proved to be a successful application. Fama \& French (2017) themselves observed the international effect of the five-factor model but the application was not successful in Japanese market Stock market beta has the significant negative effect of beta on excess stock returns. VaR outperforms CAPM beta and ES beta outperforms VaR in estimating the significance of risk and return tradeoff in Pakistan. Size anomaly is relevant when CAPM beta is used as the systematic risk factor. Size anomaly disappears when VaR and ES are used as controlling mechanism of systematic risk. Value stocks has high returns as compared to growth stocks the finding is common in all models but effect is close to zero in PSX. Cakici (2015) reports the insignificant effect of investment and profitability factor in Japan. This study on PSX supports his findings.

ES and VaR are proved to be the optimal estimate for risk and cross-sectional of return relationship with insignificant alpha value. The VaR and ES be used as the controlling mechanism of risk and return relationship as they observe the optimal effect without the contamination of idiosyncratic risk factors.

\section{Conclusions}

Unlike CAPM reporting negative risk-return relationship, VaR and ES provide a significant positive relationship between risk and cross-sectional of excess stock returns. With VaR and ES betas, the alpha gets closer to zero which signifies the PSX predictability. ES Beta is true and highly affect the stock excess returns that proves the significance of VaR and ES against CAPM beta. Three-factor cross-sectional asset pricing model provided by Fama and French $(1992,1996)$ has not provided desired results in Pakistan stock market. Negative relationship was observed with market beta and cross-sectional of stock excess returns. VaR and ES observed the risk-averse behavior of investors. An alpha value of CAPM three factor model is significant while rest of the models of $\mathrm{VaR}$ and $\mathrm{ES}$ reports insignificant alpha value restricting the autonomous effect. Well established size anomaly is not relevant in PSX when VaR and ES are used as the controlling mechanism of systematic risk. Value stocks have high returns as compared to growth stocks. Complexity observed while applying the Fama and French (2014) five-factor model on cross-sectional of excess stock returns in Pakistani stock market. Market beta in the five-factor model has significant negative effect on cross-sectional of excess stock returns. Idiosyncratic anomelies are relevant when CAPM beta is applied as the systematic risk factor. VaR 
and ES observe the risk-averse behavior of Pakistan investors. Anomalies, such as size, profitability and investment loses its significance when VaR and ES are used in model supporting the optimal risk and return tradeoff. Value stock has high returns than weak stocks in Pakistan. An alpha value of traditional five factor is significant, and for $\mathrm{VaR}$ and $\mathrm{ES}$ at $95 \%$ alpha values are insignificant which indicates that $\mathrm{VaR}$ and ES provide optimal results as compared to CAPM model. Overall the comprehensive analysis suggests that Pakistan stock market is more prone to ES factor than other systematic risk factors.

\section{References}

Basu, S. (1983). The Relationship between Earning Yields, Market Value, and Return for NYSE Common Stock: Further Evidence? Journal of Financial Economics, 12(1), 129-156.

Benz, R. (1981). The Relationship between Returns and Market Value Common Stocks. Journal of Financial Economics, 9(1), 3-18.

Black, F. (1972). Capital market equilibrium with restricted borrowing. Journal of Business, 45(3), 444 455.

Cakici, Nusret, (2015). The Five-Factor Fama-French Model: International Evidence. Available at SSRN: https://ssrn.com/abstract=2601662

Chen, D.-H., Chen, C.-D., \& Wu, S.-C. (2014). VaR and the cross-section of expected stock returns: an emerging market evidence. Journal of Business Economics and Management, 15(3), 441-459.

Degiannakis, S., \& Potamia, A. (2017). Multiple-days-ahead value-at-risk and Expected Shortfall forecasting for stock indices, commodities and exchange rates: Inter-day versus intra-day data. International Review of Financial Analysis, 49, 176-190.

Diamandis, P. F., Drakos, A. a., Kouretas, G. P., \& Zarangas, L. (2011). Value-at-risk for long and short trading positions: Evidence from developed and emerging equity markets. International Review of Financial Analysis, 20(3), 165-176.

Elton, E. J., \& Gruber, M. J. (1991). Differential information and timing ability. Journal of Banking \& Finance, 15(1), 117-131.

Fama, E.F. and French, K. R. (1989). Business Conditions and Expected Returns on Stock and Bonds. Journal of Financial Economics, 25(1), 23-49.

Fama, E.F. and French, K. R. (1993). Common Risk Factors in the Returns on Stocks and Bonds. Journal of Financial Economics, 33(1), 3-56.

Fama, E. F., \& French, K. R. (1992). The Cross-Section of Expected Stock Returns. Journal of Finance, 47(2), 427-465, http://doi.org/10.1111/j.1540-6261.1992.tb04398.x 
Fama, E. F., \& French, K. R. (2014). A five-factor asset pricing model. Journal of Financial Economics, 116(1), 1-22, http://doi.org/10.1016/j.jineco.2014.10.010

Fama, E. F., \& French, K. R. (2017). International tests of a five-factor asset pricing model. Journal of Financial Economics, 123(3), 441-463. http://doi.org/10.1016/j.jfineco.2016.11.004

Fama, E., \& MacBeth, J. (1973). Risk, return and equilibrium: empirical tests. Journal of Political Economy, 81(3), 607-636.

Hou, K., Xue, C., \& Zhang, L. (2014). Digesting Anomalies: An Investment Approach. Review of Financial Studies, 28(3), 650-705, http://doi.org/10.1093/rfs/hhu068

Jorion, P. (2002). Value at Risk: The New Benchmark for Managing Financial Risk. New York: McGraw Hil.

Jorion, P. (2006). Value at Risk: The new benchmark for managing financial risk (2nd ed.). McGraw-Hill.

Keim, D. (1983). Size-Related Anomalies and Stock Return Seasonality: Fur ther Empirical Evidence. Journal of Financial Economics, 12(1), 13-32.

Keim, D. (1986). The CAPM and Equity Return Regularities. Financial Analysts Journal, 42(3), 19-34.

Kubota, K., \& Takehara, H. (2017). Does the Fama and French Five-Factor Model Work Well in Japan? International Review of Finance, http://doi.org/10.1111/irfi.12126

Lewellen, J. (1999). The Time Series Relations Among Expected Returns, Risk, and Book-to-Market. Journal of Financial Economics, 54(1), 5-43.

Lintner, J. (1965). The valuation of risk assets and the selection of risky investments in stock portfolios and capital budgets. Review of Economics and Statistics, 47(1), 13-37.

Markowitz, H. (1952). Portfolio selection. Journal of Finance, 7(1), 77-91.

Nelson, W. R. (1999). Three Essays on the Ability of the Change in Shares Outstanding to Predict Stock Returns. Yale University.

Nguyen Nhu, Numan Ulku, \& Jin Zhang. (2015). Fama French Five Factor Model Evidence From Vietnam. University Of Otago. Unpublished Working Paper.

Novy-Marx, R. (2013). The other side of value: The gross profitability premium. Journal of Financial Economics, 108(1), 1-28.

Rachev, S. T., Stoyanov, S. V, \& Fabozzi, F. J. (2011). Risk and Uncertainty. John Wiley \& Sons. [Retrieved 2017-10-08] Available at: https://scholar.googleusercontent.com/scholar.bib?q=info:wl1_KgMcKHkJ:scholar.google.com/\& 
output=citation\&scisig=AAGBfm0AAAAAWS6qY0po3q56sz9SVI7BgZqxuObtUrb-

$\& \mathrm{scisf}=4 \& \mathrm{ct}=\mathrm{citation} \& \mathrm{~cd}=-1 \& \mathrm{hl}=\mathrm{en}$

Reinganum, M. R. (1983). The Anomalous Stock Market Behavior of Small Firms in January: Empirical Tests for Tax-Loss Selling Effects. Journal of Financial Economics, 12(1), 89-104.

Scheule, H., Kellner, R., \& Rösch, D. (2016). The role of model risk in extreme value theory for capital adequacy. The Journal of Risk, http://doi.org/10.21314/JOR.2016.337

Sharpe, W. F. (1964). Capital asset prices: a theory of market equilibrium under conditions of risk. Journal of Finance, 19(3), 425-442.

Theriou, N. G., Maditinos, D. I., \& Chadzoglou, P. (2005). The Cross-Section of Expected Stock Returns: An Empirical Study in the Athens Stock Exchange. Managerial Finance, 31(12), 58-78. 